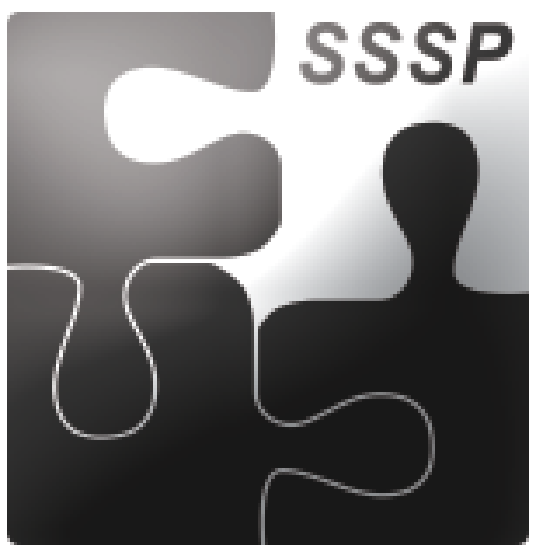

\title{
Household Crowding and Family Relations in Bangkok
}

Author(s): Theodore D. Fuller, John N. Edwards, Sairudee Vorakitphokatorn and Santhat Sermsri

Source: Social Problems, Vol. 40, No. 3 (Aug., 1993), pp. 410-430

Published by: University of California Press on behalf of the Society for the Study of Social Problems

Stable URL: http://www.jstor.org/stable/3096888

Accessed: 19/02/2014 09:03

Your use of the JSTOR archive indicates your acceptance of the Terms \& Conditions of Use, available at http://www.jstor.org/page/info/about/policies/terms.jsp

JSTOR is a not-for-profit service that helps scholars, researchers, and students discover, use, and build upon a wide range of content in a trusted digital archive. We use information technology and tools to increase productivity and facilitate new forms of scholarship. For more information about JSTOR, please contact support@jstor.org. 


\title{
Household Crowding and Family Relations in Bangkok*
}

\author{
THEODORE D. FULLER, Virginia Polytechnic Institute and State University \\ JOHN N. EDWARDS, Virginia Polytechnic Institute and State University
}

SAIRUDEE VORAKITPHOKATORN, Mahidol University

SANTHAT SERMSRI, Mahidol University

\begin{abstract}
Cities in developing countries are growing ever larger and more dense, fostering congested household environments. Using data from Bangkok, this paper examines the effect of household crowding on multiple measures of family relations, looking at the possible "social costs." The data show that objective household crowding does increase marital instability and arguments, and parent-child tensions. Subjective household crowding affects not only these three aspects of family relations, but also results in more frequent disciplining of children. These effects are largely mediated by psychological stress. The paper rejects the argument that subjective crowding is an effect, rather than a cause, of marital and family relations, and shows little difference between wives' and husbands' reactions to crowding. The consequences of household crowding, generally found to be selective and modest in North America and Europe, are stronger in Bangkok, a city with crowded conditions more typical of less developed nations.
\end{abstract}

From Durkheim ([1893] 1947) forward, most theories of social integration have viewed population size and density as facilitating the family's role as a central mechanism for the stabilization of individuals and the maintenance of broader social networks. Crowding research, especially that concerning the household or the "primary environment" (Stokols 1978), has drawn attention to the obverse (Booth 1976; Gove, Hughes, and Galle 1979; Milgram 1970), stressing the negative effects on close social bonds when there is crowding. The potential negative effect of crowding is a salient issue in less developed countries where urban populations continue to grow.

In this paper we extend prior work on household crowding as it affects families. While most of what we know about the effects of human crowding is based on North American and European studies, we seek to extend this knowledge base by presenting analyses of data collected in Bangkok, Thailand, a city in which average households are four times as crowded as those in North America. Cross-cultural research such as this has the potential not only to increase the variance in the variables of interest, but to test the generalizability of explanations. With Thai data, we can more precisely assess the "costs" when household crowding reaches levels of the magnitude typical of the non-Western world.

\section{Prior Research on Crowding}

North American studies have produced mixed findings concerning the costs of crowding.

* The research reported in this paper was supported by grant SES-8618157 from the National Science Foundation. We are grateful to the Institute for Population and Social Research, Mahidol University, Bangkok for additional support. We wish to thank Kristi Hoffman for research assistance, and Michael Hughes, Robert Liebman, Terance Miethe, Juree Vichit-Vadakan, Lee Wolfle, and the anonymous reviewers for their comments on an earlier draft of the paper. An earlier version of this paper was presented at the American Sociological Association meetings. Correspondence to: Fuller, Department of Sociology, Virginia Polytechnic Institute and State University, Blacksburg, VA 24061. 
Based on a secondary analysis of two national surveys, Baldassare (1979), for example, notes that crowding is fairly strongly related to decrements in marital relations, but that it has far less impact on the quality of parent-child relations. In a more elaborate analysis, Booth and Edwards (1976) found modest effects between different crowding measures and various aspects of spousal relations in a Toronto sample. Among wives, perceived crowding was associated with the number of husband-wife arguments, threats to leave home, and a scale assessing the quality of the spousal relationship. Although perceived crowding had no effect on measures of the parent-child relationship, objective crowding was related to the number of times parents hit their children. It is noteworthy that for men most of the anticipated relationships between perceived crowding and family relations were nonsignificant, and among both men and women most of the anticipated relationships between objective crowding and family relations were nonsignificant.

Gove and Hughes' (1983) Chicago study examined a very broad array of crowding effects. Their measures of subjective crowding, in particular, are consistently related to a lack of positive marital relations, the presence of negative relations, a low score on a marital relations balance scale, and not feeling close to one's spouse. Objective crowding is significantly related to three of the four measures of marital relations. Parents living in congested homes felt harassed by their children, were relieved when the children were outside the dwelling, showed less support for their children, and punished their offspring more frequently.

While these studies clearly document that household crowding does have some effects, the relative strength of these effects has been a matter of debate (Booth, Johnson, and Edwards 1980a, 1980b; Choldin 1978; Gove and Hughes 1980a, 1980b). On the one hand, Gove, Hughes, and Galle argue that "crowding does have substantial effects and it is time to turn away from the question of whether it ever has effects to the study of the factors which magnify or minimize its effects" (1979:79). On the other hand, Booth and his associates conclude that "household crowding is a variable of minimal importance in explaining pathology, at least in modern industrial society" (1980b:878). Such inconsistency leaves us with questions about the true effects of overcrowding.

Both aggregate-level analyses and many of those using small samples of individual-level data have been plagued with misspecified models. At the aggregate level, problems of collinearity may obtain because of the difficulty of isolating the effects of density or crowding from other predictive structural variables (Choldin and Roneck 1976; Levy and Herzog 1974; Preuss 1981; Schmitt 1966). At the individual level, many studies, usually because of small sample sizes, have failed to introduce theoretically important control variables, especially socioeconomic status. Furthermore, none of the previous research has considered the possibility that perceived crowding may be an effect, rather than a cause, of poor marital and family relations. In the face of these difficulties, assessing the intensity of crowding effects becomes impossible.

In addition to the aforementioned North American investigations, survey-based studies of the effects of crowding have been conducted in several developing countries, including the Philippines, India, Singapore, and Hong Kong (Hassan 1977, 1978; Jain 1987; Marsella, Escudero, and Gordon 1970; Mitchell 1971). Most of these studies, however, also have been plagued by problems with sampling and a lack of adequate controls. An exception, Mitchell's study, with a relatively large sample and basic controls for social class, found that household crowding has no effect on husband-wife relations, but does have some effect on parent-child relations.

The deficiencies in the few studies of crowding in the non-Western world leave us with fundamental questions unanswered. Currently, European and North American densities, especially household crowding, are relatively low by world standards. Persons per room, the most commonly used measure of household crowding, is an average of 0.5 for North America. In other countries, household crowding is three to four times this level. Moreover, multiple- 
family dwellings are far more prevalent in developing countries. To more fully determine how housing and crowding affect family relations, it is necessary to examine these relationships in a setting where housing is less adequate and crowding more intense.

\section{Household Crowding and Family Life}

Implicitly, if not explicitly, most crowding studies assume that crowding effects are mediated by psychological stress or some closely related phenomenon, such as a lack of privacy (Booth 1976; Gove and Hughes 1983). Theoretically, congested conditions are viewed as creating the necessity to interact with others, and with the multiplicity of interaction comes intensified stress or expressed demands upon an individual. As stress escalates, it becomes manifested in a person's behavior as aberrant responses. It is assumed that even if coping behaviors alleviate stress in the short term (cf. Sherrod and Cohen 1979), continued crowding ultimately results in some form of pathological reaction. This suggests two hypotheses. First, all things being equal, the higher the level of household crowding, the greater the amount of stress experienced. Second, the greater the amount of stress experienced, the higher the incidence of disturbed social relations.

This constitutes, of course, a highly restricted model, for there are numerous known and theoretically relevant effects that influence each of the model's components. Socioeconomic level, for example, is one of the more powerful predictors affecting a host of social phenomena, not the least of which is housing. People with less education and income are notoriously disadvantaged in housing markets; they are disproportionately restricted to more cramped dwellings and housing with fewer amenities. This is certainly the case for the majority of Bangkok residents. Such subgroups also are characterized by larger family size, which contributes to objective crowding and is likely to affect the perception of crowding. Indirectly, if not directly, socioeconomic status is also likely to influence the individual's ability to manage the home environment. With fewer available resources, people in lower socioeconomic groups are less apt to have the means to cope with the problems of a congested home. This may be further accentuated by large family size. Young children are often noisy and disruptive, and their activities are frequently unpredictable, adding to the difficulties of adjusting to congested settings (Baldassare 1981; Rodin and Baum 1978; Sherrod and Cohen 1979).

While some investigations have not found a very strong correlation between objective and perceived crowding (Booth 1976), with some qualifications, it is reasonable to expect a positive relationship between the two. Perceived crowding is hypothesized to relate positively to felt demands and stress. The higher the level of perceived crowding, the higher the level of stress experienced, and the more likely one is to feel that household members make excessive demands. Virtually every model of crowding effects, as well as numerous empirical studies, suggest that felt demands, stress, or some closely related phenomenon is a crucial linkage in explaining pathological behaviors (Altman 1975; Booth 1976; Desor 1972; Gove, Hughes, and Galle 1979; Levi and Andersson 1975; Milgram 1970; Stokols 1972).

The model, in turn, further suggests a positive relationship between felt stress and disturbed family relations. Past research has emphasized the crucial importance of an optimal level of stimuli for effective social behavior. Any excess stimuli tend to produce problematic behaviors (Altman 1975; Booth 1976; Desor 1972; Gove, Hughes, and Galle 1979; Welford 1974). While all social situations entail some degree of stress, we would anticipate particularly high stress levels under congested conditions. In the home environment, personal contact is inevitable, interaction is difficult to avoid, and activities are easily observable. Because of the relative intimacy involved in family life, evaluations of behavior are likely to be a more continuous part of the daily round of activities. Hence, insofar as elevated stress levels interfere with the "normal" course of interaction, higher levels of conflict between family members 
can be expected. In particular, such conflict would be manifested between husband and wife, between parents and children, and, perhaps to a lesser extent, between the primary family and other members of the household (an older generation, other relatives, or unrelated occupants). Across all categories in highly crowded conditions, qualitative assessments of relations are expected to be poorer, arguments more frequent, feelings of affect lower, physically aggressive behavior more prevalent, and child care less effectual.

All of this suggests a much less restricted model of crowding effects and a fairly complex explanation of how congested households may affect families, especially if indirect as well as direct effects are considered. The full model we test, including only the hypothesized direct relationships, is shown diagrammatically in Figure 1. It is based on the assumption that marital and family relations are dependent variables with no effect on their presumed causes. Later we relax this assumption, and consider the possibility of reciprocal effects.

Control

Variables

Sex of respondent

Socioeconomic status

Family life cycle

Housing quality

Household control

Household

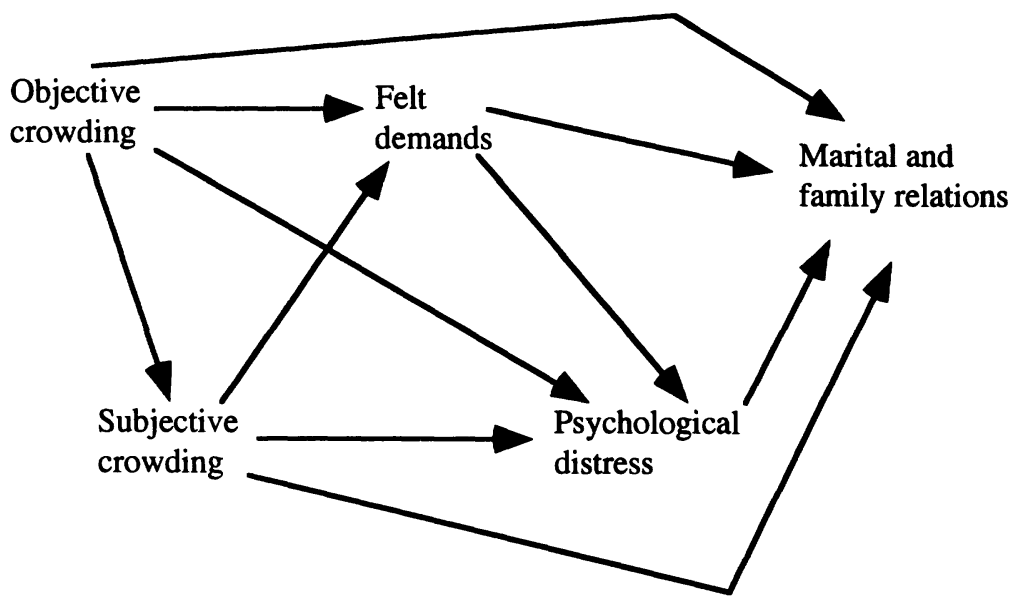
structure

\section{The Thai Context}

Bangkok represents one of the more striking examples of an urban primacy. Its population, as recently as 1960 numbering some 1.8 million, now exceeds 6 million. As the center of commerce, finance, manufacturing, and trade, Bangkok dominates the entire economic fabric of the country, as well as nearly every other sphere of Thai culture-political, religious, and educational. Bangkok's primacy is illustrated by the fact that in 1980 its population was more than 50 times larger than Thailand's second largest city (Sternstein 1984:67), and over 60 percent of the urban population of Thailand resided in Bangkok (Fuller 1990).

Hong Kong is often mentioned as one of the most crowded cities in the world. But Bangkok's level of crowding is comparable to that of Hong Kong. While the average number of persons per room is 2.1 in Bangkok, in Hong Kong the average is 1.9 (United Nations 1985). 
A number of crowding researchers have suggested that the reactions to crowding may be conditioned by the cultural context (Booth 1976; Gove and Hughes 1983). While the level of household crowding in Bangkok is obviously high by North American standards, suggesting that we might find strong effects, there are several possible ameliorating cultural factors.

First, the typical household structure found in Bangkok suggests that there may be normative tolerance for household crowding. Few Bangkokians live alone, extended families are fairly common, and the average household size is more than five persons. Whether these living arrangements are a matter of necessity or choice, social norms may facilitate harmonious relations among crowded family members. A second, and related, aspect of Thai normative structure is the stress on avoiding interpersonal conflict and maintaining harmonious relations (Klausner 1972, 1981). The emphasis placed on self-control may moderate any potential effects of crowding. Third, even in rural areas, where land is relatively abundant, similar levels of persons per room are found. Fourth, the tropical climate allows household members to be out-of-doors many hours every day, during all seasons of the year. Living space is not confined to the housing unit itself, but expands to adjacent communal areas. Moreover, in Bangkok, those who work outside the home often work long hours and may have a time-consuming commute to work. This means that some household members are absent during most of their waking hours. Finally, Thais appear to value social interaction more than people in the United States, while placing less value on privacy. Where someone in the United States may wonder whether it is appropriate to disturb a person who is alone, Thais are more likely to think that someone who is alone may need companionship. For Thais, crowding may provide protection from loneliness and offer opportunities for social interaction.

\section{Methods}

\section{The Sample}

The population of interest in this study was intact married couples living in Bangkok in 1988 who had at least one child and where the mother was not more than 45 years of age. Since stress is central in our model and since migration can be a stressful experience, recent migrants (living in Bangkok less than one year) were excluded. Using a two-stage, probabilityproportional-to-size, cluster sample design, we selected a representative sample of 2017 households and interviewed either a wife or a husband in each household. A total of 1399 wives and 618 husbands were interviewed by trained native Thai interviewers. ${ }^{1}$ The response rate was 87 percent.

Bangkok is divided administratively into 24 districts comprising a total of 150 subdistricts. Three districts that are administratively within Bangkok but which have comparatively low density were omitted from the sampling frame. These three districts, which included only 3.2 percent of the total population of Bangkok, had a population density only one-fifteenth as high as that for the remaining districts ( 313 persons per square kilometer, compared to an average of $\mathbf{4 6 9 0}$ persons per square kilometer).

The National Statistical Office (Bangkok) used probability-proportional-to-size sampling to select 45 subdistricts. The districts were first arranged by population density in order to implicitly impose stratification by population density. Next, the National Statistical Office used probability-proportional-to-size sampling to select three blocks from each subdistrict. Detailed

1. Ideally, we would have the same number of husbands and wives. Commenting primarily on U.S. surveys, Gove and Hughes (1979:133) note that "this oversampling of women appears to be a characteristic of household surveys." The greater number of wives presumably reflects their greater availability. Since we control for sex of respondent, the undersampling of men should not affect the pattern of the relationships. 
block maps showing each housing unit in the sample blocks were used as the sampling frame to randomly select households to be interviewed.

While the average level of household crowding in North America is 0.5 persons per room, in our representative sample of households in Bangkok, less than one percent of households had such a low level of crowding. The average number of persons per room was 2.1 , with a standard deviation of 1.3. It should be noted, however, that while the level of crowding was high by the industrialized world's standards, there was a wide range of crowding represented in our sample. While 22 percent of the households had no more than one person per room, there were at least two persons per room in over 40 percent, at least three in over 20 percent, and at least four per room in over 10 percent of the households. In terms of area, the average number of persons per 100 square meters was 12.25 . To reach the same level of household crowding in the United States, a 1500 square foot home would have to house 17 people.

The sample design did not yield an unusually crowded sample of households. The 1980 census of Bangkok (National Statistical Office 1983) found: (1) 92 percent of households are made up of families; (2) only 1 percent of persons live alone; and (3) the average household size is 5.1 in Bangkok for all households, including nonfamily households, compared to our result of 5.5. Also, the percentage of Bangkok family households that are nuclear ( 76 percent), as opposed to vertically or horizontally extended, is quite similar to that found in our sample (72 percent).

\section{Measurement}

Whenever measures developed in one culture are used in another culture, special sensitivity must be shown to their portability, since the absence of cultural equivalents can undermine their validity. Taking this into account in the initial phase of the investigation, we conducted a series of ten focus group interviews, using Thai moderators. The focus groups each comprised about eight volunteers, homogeneous with respect to sex and family type (nuclear and compound families).

A key objective of the group interviews was to explore whether our basic concepts had any meaning to Thais. Many contend, for example, that Asians in general and Thais in particular are inured to whatever consequences crowding may have for Occidentals (Loo and Ong 1984). Given a history of household congestion, human adaptability, some argue, can largely negate any adverse consequences (Baldassare 1979; Booth 1976). Many focus group participants attested, however, to the perception of crowding and the stress associated with it, and indicated a variety of ways in which congested conditions interfered with their daily activities (Fuller et al. 1989). Most focus group participants considered living in crowded conditions a necessity, not an matter of individual preference. A common Thai saying, "lots of people, lots of issues," echoes our theoretical model. It is clear that not only the concept of crowding but also other central concepts in our model are not peculiarly Western notions.

The focus group interviews: (1) made evident some of the Thai norms concerning marital and family relations, including expectations about marital companionship; (2) provided a rich source of information about family interaction and conflict, manifestations of stress, and perceptions of crowding in the Bangkok context; (3) furnished insights into the effects of crowding on family relations; and (4) contributed to the development of our survey instrument (Fuller et al. 1993). Based on previously used Western measures as well as the experience of the group interviews, the interview schedule evolved through a series of back-translations between English and Thai. In the process, the everyday language of Thais used in the focus groups was incorporated into the survey instrument. Additional modification resulted from a pretest of the instrument.

Confidence in the meaningfulness of the measures was further bolstered by their reliability. Scale reliability was comparable to, and in a few instances higher than, that reported in 
the Western studies from which the scales were originally adopted. We would not expect scales to behave in a reliable way if their items did not have inherent meaning to the respondents.

\section{Analysis Procedure}

Structural equation modeling, specifically LISREL 7 (Joreskog and Sorbom 1989), was used to estimate the effects examined in this paper. Structural equation modeling is especially useful when there are multiple indicators of theoretical variables. The indicators used for each of our theoretical variables are shown in the Appendix. The Appendix also includes "measurement notes" that document correlated error terms found among indicators for specific theoretical variables.

\section{Independent Variables}

A standard measure of objective crowding is persons per room (Baldassare 1979; Booth 1976; Gove and Hughes 1983). In this paper, we use three indicators: persons per room, persons per 100 square meters in the dwelling unit, and "others per room," which took into account the overlapping times when different household members were actually at home. Others per room used in its numerator the number of people other than the respondent who were in the household when the respondent was at home and awake, where the unit was the person-hour. This information was taken from a time-budget detailing the week day immediately preceding the interview. Together, these three indicators provided a better measure of objective crowding than would any one measure alone.

The measure of subjective crowding was based on four agree-disagree items, derived from the Toronto study (Booth and Edwards 1976). The items were scaled so that a higher score meant the respondent felt more crowded. The specific items that composed this scale and all other scales used in this paper are listed in the Appendix. ${ }^{2}$

Preliminary analyses showed that both objective and perceived crowding tended to have a diminishing effect on the dependent variables at the higher levels of crowding. Objective crowding had a diminishing effect when the persons per room were above 2.5 , or about the 75 th percentile. Perceived crowding tended to have a diminishing effect at about the 90th percentile. This is not to say that marital and family relations improved beyond a certain level of crowding; rather, the pattern suggests a ceiling effect. We logged the indicators of objective and subjective crowding to take this ceiling into account.

\section{Dependent Variables}

A Thai cultural ideal is that harmony should reign in the family. Spouses should care for one another. Parents should love and protect their children. Children should respect their parents. The individual gains physical, psychological, social, and economic sustenance within the family. But is this ideal a reality? Particularly in crowded households, our theoretical model would suggest this prized harmony and the avoidance of conflict will be difficult to achieve. It was clear from our focus group discussions that marital harmony for these individuals was especially elusive. This was amply illustrated in several of the group exchanges.

2. With one exception, the items for each concept compose a single factor, as determined by factor analysis. The exception is the items measuring housing satisfaction, for which factor analysis identified three factors but retained an acceptable reliability when grouped. Scales were formed by summing the raw values of the component items. As an indication of the reliability of the measures, Cronbach's alpha was calculated for each multi-item concept. The alpha coefficients, ranging from .61 to .85 , indicate that all of the theoretical variables have a satisfactory level of reliability. Omission of any item from a scale would result in a lower reliability coefficient for that scale. 
Malee: We don't have to show that we love anymore. If I do it, it would be so awkward.

Chalerm: I want a divorce, I want him to go. I only think of sewing. When he's drunk, he is very disgusting.

Chamnian: I'm not interested in seeing his face, but I am in his money.

Lamjai: I usually don't know where he goes. I don't care. My neighbor used to ask me how could I live with him not knowing what he does.

In another focus group, one respondent stated:

Sukit: In my case, we also used to fight very often. But for the last few years, I felt that violence is no solution. The best solution is silence. Let her complain, let her do it whether she's right or wrong. I'd only keep quiet, and it works. Eventually she stops, tensions are eased. As a matter of fact, I sympathize with her somehow. She only stays home, not much activity, no variety in life, monotonous. Of course, she is sure to have some frustrations, which she ought to let out. So, just take that. Let her breathe out her frustrations, just like a radio station left turned on, don't pay attention.

Respondents in a third focus group suggested that the discord extended to relations with children.

Moderator: What do you do when they get carried away with their playing?

Attaporn: I scream at them, and I often get physical with them too. . . . I can't take a lot of that. As I said, I feel like I will have a nervous breakdown (laughter).

Rattanaporn: When it gets that way in my house, I will blow up. ... I'll hit and I'll scold. I don't do a lot of that now as my children are pretty much grown up. When they were younger, I remember I hit them almost every day. Even at that, they often got out of hand. The good thing was that the flat has the area downstairs. [Flats are constructed with an open area at ground level where children can play and people can congregate.] If we had to live all the time in the flat together, it would have been unbearable to live together in good health, both children and parents.

Moderator: Why do you get so upset to hit them everyday?

Rattanaporn: They are both stubborn and disobedient, so I must hit them.

Moderator: And what do they do?

Rattanaporn: They cry, of course (laughter).

These excerpts from the focus group interviews illustrate the conflict and discord found in many Thai households. To what extent is such conflict related to household crowding? To address this question rigorously, it was necessary to systematically measure the quality of family relations. Our research considered three theoretical constructs dealing with the marital relationship and three bearing on parent-child relations.

Many researchers use the term "marital instability" to denote divorce, yet that term more appropriately designates a "shaky" intact marriage. It constitutes the negative pole of a continuum of marital cohesion (Booth et al. 1984). Marital instability has two dimensions. The cognitive dimension has to do with what people think about their marriage, while the behavioral component concerns actions based on these thoughts. As one dependent variable in our analyses, we used a short form of a marital instability scale developed in the United States to investigate marital change over the life course (Booth, Johnson, and Edwards 1983; Edwards, Johnson, and Booth 1987). (See Appendix for all scale items.) A higher score suggests a more unstable marriage.

A second construct involved another negative aspect of marital relations, "marital arguments." A higher score designates poor marital relations. The third marital relations scale measured positive affect or "marital companionship." The higher the score, the more frequently couples did things together and displayed positive affect.

If crowding has adverse consequences for the parent-child relationship, we would expect parents in congested households to be less supportive of their children, to feel more tension in 
this relationship, and to discipline their children more frequently. Higher scores mean, respectively, that the parent was more supportive, experienced greater tension, and disciplined the child(ren) more frequently.

\section{Intervening Variables}

Two theoretical constructs, felt demands and psychological distress, were used as intervening variables. Unlike Gove and Hughes (1983), we see felt demands as a result of subjective crowding, rather than as an aspect of subjective crowding. Felt demands, a scale derived from the Chicago study, was based on four items indicating the extent to which the respondent felt that other household members made many demands on him or her. The higher the score, the more perceived demands the person reported.

As Mirowsky and Ross (1989) point out, psychological distress has two major formsdepression and anxiety. According to Mirowsky and Ross (1989) and Dohrenwend et al. (1980), depression and anxiety are not clearly distinct, but instead are closely intertwined. Tapping the broader concept of felt stress, our measure of psychological distress comprised ten items that reflect various symptoms, including aspects of both anxiety and depression. A higher score indicates greater distress.

\section{Control Variables}

Clearly, marital and family relations may be affected by many factors other than household crowding and the intervening variables posited in our model. For example, the number and ages of a couple's children can affect the marital relationship. In addition, the presence of parents, parents-in-law, or married siblings in the same household may affect the quality of marital and parent-child relations.

To separate these other effects, the analyses included controls for socioeconomic status, stage in the family life cycle, household structure, housing quality, and household control. Two measures of socioeconomic status were used: family income and respondent's education. Education was measured by the number of years of formal education completed. The stage in the family life cycle was indicated by three variables: the number of the respondent's preschool, elementary school, and high school age children living in the household. Two aspects of household structure were included as controls: whether the household included two or three generations and the number of married couples in the household.

In prior studies by Baldassare $(1979,1981)$ and by Gove and Hughes (1983), household control was indexed by position in the household. We have attempted to measure household control more directly and as a continuous variable rather than as a nominal variable. Specifically, household control was a scale based on three items that indicate the extent to which a respondent perceives that he or she has the authority to make decisions within the household without consulting others. A higher score indicates more household control.

Quality of housing was measured subjectively by a variety of items. "Housing satisfaction" comprised 11 items that indicate the extent to which a respondent was satisfied with various specific aspects of his or her housing. A higher score on the housing satisfaction scale designates greater satisfaction.

Thus, a total of ten control variables, some of which were multi-item scales, were used in the multivariate analyses.

\section{Results}

The zero-order correlations show that objective crowding is modestly, but significantly, 


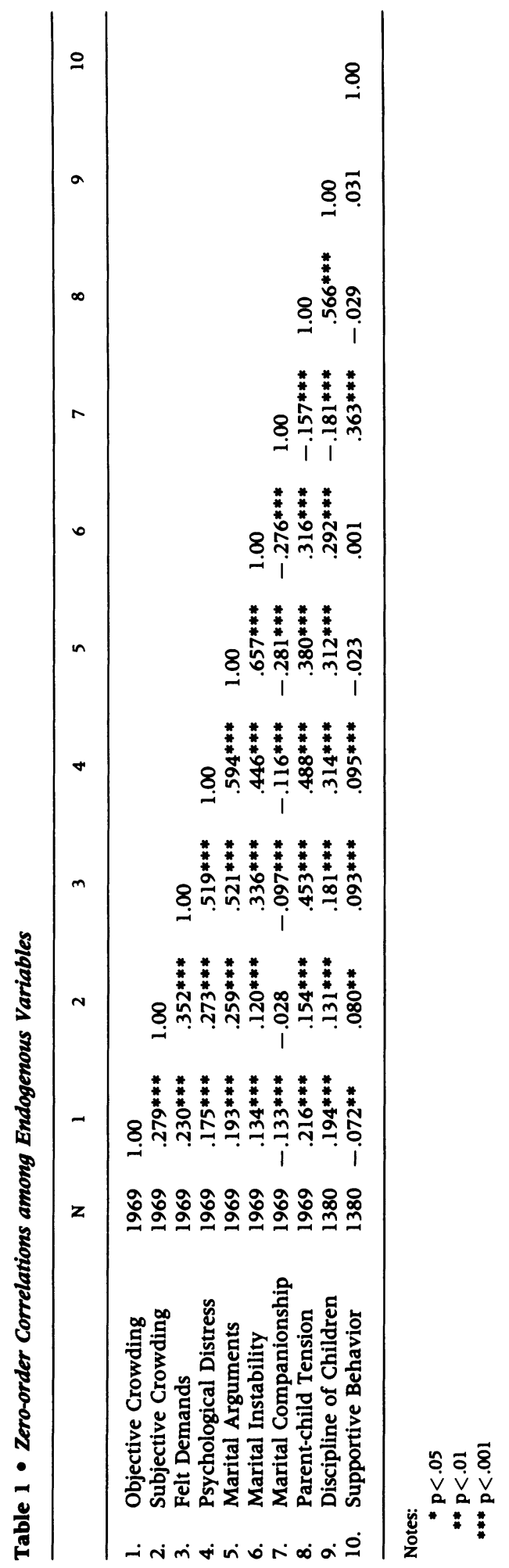


related to each of the marital and family relations measures. As anticipated, higher levels of objective crowding are associated with greater marital instability, more marital arguments, less companionship, more parent-child tension, more disciplining of children, and less supportive behavior (Table 1). Similarly, parents who feel more crowded are more likely to argue with their spouses and to have more marital instability. At the same time, they report more parent-child tension and discipline their child(ren) more. However, perceived crowding is not related to marital companionship, and those who feel more crowded, contrary to expectations, are more supportive of their children.

The top panel of Table 2 shows the total effects of the independent variables (objective and perceived crowding) and the intervening variables (felt demands and psychological distress) on the marital and family relations measures, based on a fully recursive model. The ten

Table 2 - Unstandardized Total Effects and Standardized Direct Effects among Endogenous Variables, Fully Recursive Model

\begin{tabular}{|c|c|c|c|c|c|}
\hline \multirow[t]{2}{*}{ Dependent Variable } & \multicolumn{4}{|c|}{ Unstandardized Total Effects } & \multirow{2}{*}{$\begin{array}{c}\text { Squared } \\
\text { Multiple } \\
\text { Correlation }\end{array}$} \\
\hline & $\begin{array}{l}\text { Objective } \\
\text { Crowding }\end{array}$ & $\begin{array}{l}\text { Subjective } \\
\text { Crowding }\end{array}$ & $\begin{array}{c}\text { Felt } \\
\text { Demands }\end{array}$ & $\begin{array}{l}\text { Psychological } \\
\text { Distress }\end{array}$ & \\
\hline $\begin{array}{l}\text { Subjective Crowding } \\
\text { Felt Demands } \\
\text { Psychological Distress } \\
\text { Marital Arguments } \\
\text { Marital Instability } \\
\text { Marital Companionship } \\
\text { Parent-child Tension } \\
\text { Discipline of Children } \\
\text { Supportive Behavior }\end{array}$ & $\begin{array}{l}.089^{* * *} \\
.132^{* * *} \\
.149 * * * \\
.150^{* * *} \\
.041^{* *} \\
-.017 \\
.123^{* * *} \\
.029 \\
-.023\end{array}$ & $\begin{array}{l}.570^{* * *} \\
.733^{* * *} \\
.505^{* * *} \\
.109 * * \\
.081 \\
.275^{* * *} \\
.121^{*} \\
.187^{* *}\end{array}$ & $\begin{array}{c}.794^{* * *} \\
.592^{* * *} \\
.206^{* * *} \\
-.091 \\
.573^{* * *} \\
.095^{* *} \\
.097^{* *}\end{array}$ & $\begin{array}{l}.306^{* * *} \\
.136^{* * *} \\
-.097^{*} \\
.275^{* * *} \\
.114^{* * *} \\
.031\end{array}$ & $\begin{array}{l}.434 \\
.234 \\
.097 \\
.385 \\
.361 \\
.095\end{array}$ \\
\hline \multirow{2}{*}{ Supportive Behavior } & \multicolumn{5}{|c|}{ Standardized Direct Effects } \\
\hline & $\begin{array}{l}\text { Objective } \\
\text { Crowding }\end{array}$ & & tive & $\begin{array}{c}\text { Felt } \\
\text { Demands }\end{array}$ & $\begin{array}{c}\text { Psychological } \\
\text { Distress }\end{array}$ \\
\hline Subjective Crowding & $.205^{* * *}$ & & & & \\
\hline Felt Demands & $.102 * * *$ & & $2 * * *$ & & \\
\hline Psychological Distress & .015 & & $2^{* *}$ & $.477 * * *$ & \\
\hline Marital Arguments & .053 & & & $.288 * * *$ & $.420 * * *$ \\
\hline Marital Instability & .024 & & & $.151 * * *$ & $.350 * * *$ \\
\hline Marital Companionship & -.010 & & & -.006 & $-.082^{*}$ \\
\hline Parent-child Tension & .043 & - . & & $.260 * * *$ & $.335 * * *$ \\
\hline Discipline of Children & .015 & & & .020 & $.263 * * *$ \\
\hline Supportive Behavior & -.074 & & & .093 & .062 \\
\hline
\end{tabular}

Notes:

Controlling for sex, socioeconomic status, family life cycle, housing quality, household control, and household structure.

${ }^{*} \mathrm{p}<.05 \quad * * \mathrm{p}<.01 \quad * * * \mathrm{p}<.001$

control variables mentioned above are included in the analyses. The specific magnitude estimated for the relationship among the independent and intervening variables fluctuated slightly depending on which measure of marital or family relations was included in the model. However, all six hypothesized relationships among the independent variables are significant and positive regardless of which dependent variable is being analyzed. People who live in more crowded households feel more crowded, feel that more demands are made on them, and experience more psychological distress. In turn, people who feel more crowded, feel that family members are making more demands on them, and feel more psychological 
distress. In addition, people who feel that others are making many demands on them feel more psychological distress.

The last six rows of the top panel of Table 2 come from six different LISREL runs, one for each dependent variable. These results provide broad support for the model. While the effect of objective crowding is not as consistent as anticipated, it does significantly increase marital arguments, marital instability, and parent-child tensions.

Perceived crowding significantly affects five of the six outcome measures. Contrary to expectations, however, it increases supportive behavior, possibly a compensatory reaction. The total effects of felt demands are very similar to those for perceived crowding. Finally, the effects of psychological distress are the most consistent with expectations. Those who have more distress have more marital arguments and greater marital instability, they have less marital companionship, feel more tension in their interactions with their child(ren), and discipline their children more. Distress has no significant total effect on supportive behavior.

A more complete picture of the effects of crowding can be obtained by examining direct effects. As shown in the bottom panel of Table 2, fewer of the hypothesized links are significant when direct effects are examined. Objective crowding still significantly increases subjective crowding and felt demands, but it has no significant effect on distress or on any of the dependent measures after controlling for perceived crowding and the intervening variables. Thus, the significant total effects of objective crowding on marital arguments, instability, and parent-child tension are fully explained by the effect of objective crowding on perceived crowding and felt demands.

Perceived crowding has a significant direct effect on felt demands and on distress, but this subjective dimension of crowding has a significant direct effect on only one of the dependent measures: the unanticipated positive effect on supportive behavior. Felt demands has a significant direct effect on distress, marital arguments, marital instability, and on parent-child tensions. The significant direct effects of distress are, of course, the same as its significant total effects.

Looking at the predictive power of the model, the squared multiple correlation is highest for marital arguments (.434) and is lowest, but still substantial, for marital companionship (.097) and supportive behavior (.095).

\section{Goodness-of-Fit}

Chi-square is a well-known measure of the goodness-of-fit of a LISREL model, but not necessarily the best indication of goodness-of-fit (Joreskog and Sorbom 1989). ${ }^{3}$ Joreskog and Sorbom (1989:43-44) point out that a reasonable use of chi-square measures is in comparative model fitting, i.e., comparing the chi-square for two similar models to assess whether the change from one model to the next represents a significant improvement or deterioration in the fit of the model. Chi-square is used in this way in the next section.

According to Joreskog and Sorbom, "the first and most obvious way of assessing the goodness of a model is to examine the results of an analysis" (1989:41). Beyond this, several specific measures are computed by LISREL, including the squared multiple correlations reported above. For the six models predicting aspects of marital and family relations, the goodness-offit index exceeds .95, the adjusted goodness-of-fit index exceeds .94, and the root mean square residual is less than .04 . These values suggest that the models provide a good fit with the data.

3. Although chi-square may be viewed theoretically as a test statistic, Joreskog and Sorbom emphasize that, since chi-square is not only sensitive to sample size but also very sensitive to departures from multivariate normality of the observed variables, such a use of chi-square "is not valid in most applications" (1989:43). While chi-square is sensitive to departures from multivariate normality, the LISREL estimates are robust if the sample size is greater than 400 (Boonsma 1983). The sample size in the present study is large enough to suggest that both the LISREL estimates and the estimates of standard errors are robust. 


\section{Reciprocal Effects}

While we have posited a particular causal order among the variables, it is entirely possible that a different causal order applies. We have argued that perceived crowding can be detrimental to marital and family relationships, but perhaps the reverse better describes the situation. Does tension and conflict with close family members cause people to feel crowded? Similarly, do excessive felt demands detract from the quality of marital and family relationships, or, rather, do the normal demands made by spouses and children seem especially onerous when relationships with them are poor? Does psychological distress erode relationships with spouses and children, or do poor relationships with spouses and children produce psychological distress? Of course, these need not be "either-or" propositions; reciprocal effects may exist.

Reciprocal effects can be most reliably detected with panel data, which we do not have. With cross-sectional data and a fully recursive model, it is impossible to examine reciprocal effects, due to the identification problem. However, LISREL permits estimation of reciprocal effects with cross-sectional data in certain circumstances. ${ }^{4}$ Essentially, "trimming" the model may permit estimation of reciprocal effects. We summarize our procedure and results below.

We eliminated nonsignificant paths from the original fully recursive models in order to estimate reciprocal effects. ${ }^{5}$ When a model is "trimmed" in this way, chi-square almost inevitably increases, indicating a poorer fit with the data. This may not, however, result in a significant deterioration in the model's fit. It is possible to determine whether the fit is significantly poorer by evaluating the change in chi-square between two models in light of the change in the number of degrees of freedom. The results show that for none of the six dependent variables does the final trimmed model have a significantly poorer fit with the data, compared with the fully recursive model.

To estimate the effects of the marital and family relations variables on subjective crowding, felt demands, and psychological distress, paths were added in each of the six models from the marital or family relations variable to the three named endogenous variables. The effects of the independent and intervening variables on the six measures of marital and family relations, as estimated by the fully recursive and nonrecursive models, are quite similar.

More importantly, none of the effects of marital and family relations on subjective crowding, felt demands, and psychological distress is significant. Also, when these feedback links are added to the models, there is no significant improvement in chi-square, compared to the trimmed models. While we had not hypothesized significant feedback effects, it can be plausibly argued that these effects could have been significant. Without testing these effects, we could not know conclusively whether crowding and the intervening variables affect marital and family relations or whether the reverse holds true. Finding no significant feedback links lends a great deal of credence to the argument that household crowding is detrimental to marital and family relationships. We contend, on the grounds of parsimony, that the original, recursive model is more appropriate than the nonrecursive model.

4. One requirement is that the model not be fully recursive. The other requirement is that in order to estimate the reciprocal effects between two variables (say, subjective crowding and marital companionship), at least one predictor variable (instrument) for each endogenous variable (i.e., a variable that is not used as a predictor for the other endogenous variable) must exist. If, for example, the number of generations in the household affects subjective crowding but not marital companionship, then number of generations may be used as an instrument of subjective crowding.

5. We first eliminated nonsignificant paths from exogenous variables to endogenous variables (i.e., nonsignificant elements of the "Gamma" matrix). Next, we eliminated nonsignificant paths among the endogenous variables (i.e., in the "Beta" matrix). However, when some nonsignificant paths are eliminated, other originally nonsignificant paths may become significant. By examining diagnostics ("modification indices") from preliminary LISREL analyses, we could detect which originally nonsignificant paths should nevertheless be retained in the model, and we retained these paths. 


\section{Interaction Effects}

Both Gove and Hughes (1983) and Booth and Edwards (1976) considered the possibility that women are more reactive to crowding than are men. Gove and Hughes (1983) argue that, in the United States, women are more attentive to other members of the household and have greater household responsibilities, and, therefore, may have a greater response to crowding. Empirically, both Booth and Edwards (1976) and Gove and Hughes (1983) present data suggesting that crowding has a greater effect on family relations for women. Both teams reach their conclusions by noting that certain effects are significant for women, but not for men. Unfortunately, significance tests for these differences are not reported.

Although the focus group interviews did not generate specific evidence to suggest that a similar gender difference in reactivity to crowding would be found in Bangkok, Gove and Hughes' theoretical argument also would seem to apply in Thailand. That is, compared to Thai men, Thai women are more attentive to the needs of other members of the household and have greater household responsibilities. Therefore, we entertained the possibility of a similar interaction effect in Bangkok.

To test this possibility, we examined the results of the multiple regression models, after including sex-objective crowding and sex-perceived crowding interaction terms. For this purpose, scales were created by summing the items involved in each theoretical construct. The alpha coefficients indicate that all of the theoretical variables have a satisfactory level of reliability (see Appendix). Persons per room was used as our indicator of objective crowding.

Although wives report higher marital instability and more marital arguments than husbands do, none of the sex interaction terms is significant for any of the measures of marital relations. Similarly, although mothers report more parent-child tension and discipline their children more than fathers do, none of the sex interaction terms is significant for any of the measures of parent-child relations. Disaggregated analyses do reveal that perceived crowding increases parent-child tensions for mothers, but not fathers; however, the effect for mothers is not significantly greater than for fathers. Since none of the differences between men and women is statistically significant, it does not appear that mothers are more reactive to crowding than are fathers. The discrepancy between our results and those of the teams cited above may be due to cultural differences, or may be simply that we used statistical tests, while they did not.

Mitchell (1971), in his study in Hong Kong, raised the possibility of another interaction effect. He argued that interpersonal conflict and stress were more likely to result when more than one family occupied a single housing unit, and that the effects of household crowding would be greater in such multifamily households. By introducing the appropriate interaction terms, we examined the possibility that household crowding, in its objective and subjective dimensions, has a greater effect in three-generation households than in two-generation households, and, alternatively, that household crowding has a greater effect when more than one married couple is in the household, as compared to only one married couple.

We find little evidence that, in Bangkok, the effects of household crowding are exacerbated by these aspects of household composition. Our finding, however, does not totally contradict Mitchell's results. First, household structure in Bangkok differs from that in Hong Kong. Mitchell referred primarily to the effects of multiple, unrelated families sharing a housing unit. Such household types are rare in Bangkok. Second, Mitchell in fact found that the number of families sharing a dwelling unit affects only emotional illness, not family relations, and then only in special circumstances, e.g., particularly among those who live above the fifth floor. Few housing structures in Bangkok, however, have more than five floors. 


\section{Summary and Conclusions}

Previous studies of the effects of household crowding in North America provide minimal guidance as to the effects of crowding on marital and family relations in the context of the higher levels of crowding found in many areas of the world. Previous survey-based studies of the effects of household crowding on marital and family relations in developing countries, where such conditions exist, have suffered from various defects that this study attempts to avoid. These defects include poor measures of family relations, inadequate samples, and inadequate controls for socioeconomic status and other relevant variables. This study has attempted to examine the effects of household crowding on marital and family relations in a context of relatively high household crowding, while maintaining a high level of methodological rigor.

Our focus group interviews provided substantial evidence that many Thais living in Bangkok do indeed perceive household crowding to be aversive. The group interviews also revealed a substantial degree of conflict among family members. What could not be determined from the group interviews, and what we attempted to ascertain from the household survey, is the extent to which household crowding accounts for the quality of the relationships between husbands and wives and between parents and children.

Although the findings are complex, we find support for the notion that both objective and subjective household crowding are detrimental to various aspects of marital and family relations, controlling for important background characteristics. Both have significant effects on marital arguments and marital instability. Perceived crowding, though, has more pervasive effects on parent-child relations. It affects supportive behavior, discipline of children, and parent-child tension, while objective crowding affects only the latter variable.

Both felt demands and psychological distress emerge as intervening variables having important effects on marital and family relations. People with more psychological distress or who feel greater demands have relatively poor marital and family relations, compared to others who feel fewer demands or who experience less distress. The effects of distress are consistently greater than the effects of felt demands. Furthermore, once felt demands and psychological distress are added to our model, perceived crowding has only one significant direct effect on the outcome measures, and objective crowding has none. Taken together, these findings strongly suggest that stress and felt demands are important explanatory variables in accounting for crowding outcomes.

Like previous researchers, we have posited that the causal ordering runs from household crowding, felt demands, and psychological distress to marital and family relations. Previous researchers, however, have not explicitly considered the possibility of feedback. Based on our empirical analyses of nonrecursive models, we conclude that the direction of causal influence is largely, if not totally, from household crowding to marital and family relations.

While previous researchers have reported stronger crowding effects for wives than for husbands, we find no such differences. Nor do we find any substantial differential effects related to the family composition of the household.

Although the Bangkok context might suggest household crowding would produce little effect-as mentioned in our discussion of the Thai setting-Bangkokians are not so inured to crowding that it no longer has an effect on their lives. In fact, compared to the results of North American and European studies, the effects of crowding on Thai family life are far less selective and have even stronger detrimental consequences.

It may well be that the effects observed here represent a ceiling, a point beyond which congested circumstances do not create ever larger decrements in social relations. But even if this is the case, it does not suggest complacency. With unabated population growth, 1.1 billion people are expected to be added to the world's population in the next decade alone. Most of this growth will be concentrated in cities in the less developed regions of the world, where 
the provision of housing stock is especially problematic. The result, in all probability, will be cities of higher density, with more intense crowding at the household level. If our results are generalizable, this suggests that families in many cities, especially in major metropolitan areas, will experience decrements in the relations between spouses and between parents and their children.

\section{References}

Altman, Irwin

1975 The Environment and Social Behavior: Privacy, Personal Space, Territory, and Crowding. Monterey, Calif.: Brooks/Cole.

Baldassare, Mark

1979 Residential Crowding in Urban America. Berkeley, Calif: University of California Press.

1981 "The effect of household density on subgroups." American Sociological Review 46:110118.

Boonsma, Anne

1983 "On the robustness of LISREL (maximum likelihood estimation) against small sample size and non-normality." Ph.D. diss., University of Groningen, The Netherlands.

Booth, Alan

1976 Urban Crowding and Its Consequences. New York: Praeger.

Booth, Alan, and John N. Edwards

1976 "Crowding and family relations." American Sociological Review 41:308-321.

Booth, Alan, David R. Johnson, and John N. Edwards

1980a "Reply to Gove and Hughes." American Sociological Review 45:870-873.

1980b "In pursuit of pathology: The effects of human crowding (comment on Gove, Hughes, and Galle, American Sociological Review, February 1979)." American Sociological Review 45:873-878.

1983 "Measuring marital instability." Journal of Marriage and the Family 45:387-394.

Booth, Alan, David R. Johnson, Lynn White, and John N. Edwards

1984 "Women, outside employment, and marital instability." American Journal of Sociology 90:567-583.

Choldin, Harvey

1978 "Urban density and pathology." In Annual Review of Sociology, ed. Ralph H. Turner, James Coleman, and Renee C. Cox, 91-113. Palo Alto, Calif.: Annual Reviews, Incorporated.

Choldin, Harvey, and Dennis W. Roncek

1976 "Density, population potential and pathology: A block level analysis." Public Data Use 4:19-30.

Desor, J. A.

1972 "Toward a psychological theory of crowding." Journal of Personality and Social Psychology 21:79-83.

Dohrenwend, Bruce P., Patrick E. Shrout, Gladys G. Egri, and Fredrick S. Mendelson

1980 "Nonspecific psychological distress and other dimensions of psychopathology." Archives of General Psychiatry 37:1229-1236.

Durkheim, Emile

[1893] The Division of Labor in Society. Translated by George Simpson. Glencoe, Ill.: The Free 1947 Press.

Edwards, John N., David R. Johnson, and Alan Booth

1987 "Coming apart: A prognostic instrument of marital breakup." Family Relations 36:168170. 
Fuller, Theodore D.

1990 "Internal migration in Thailand." In International Handbook on Internal Migration, ed. Charles B. Nam, William J. Serow, and David F. Sly, 345-369. New York: Greenwood.

Fuller, Theodore D., John N. Edwards, Sairudee Vorakitphokatorn, and Santhat Sermsri

1989 "Crowding and family relations in Bangkok: An exploratory study." Paper given at the Southern Sociological Society, Charlotte, N.C.

1993 "Using focus groups to adapt survey instruments to new populations: Experience from a developing country." In Successful Focus Groups: Advancing the State of the Art, ed. David L. Morgan, 89-104. Newbury Park, Calif.: Sage.

Gove, Walter R., and Michael Hughes

1979 "Possible cause of the apparent sex differences in physical health: An empirical investigation." American Sociological Review 44:126-146.

Gove, Walter R., and Michael Hughes

1980a "Reexamining the ecological fallacy: A study in which aggregate data are critical in investigating the pathological effects of living alone." Social Forces 58:1157-1177.

$1980 \mathrm{~b}$ "The effects of crowding in the Toronto study: Some methodological and empirical questions (comment on Booth, Johnson, and Edwards, 1976)." American Sociological Review 45:864-870.

1983 Overcrowding in the Household: An Analysis of Determinants and Effects. New York: Academic Press.

Gove, Walter R., Michael Hughes, and Omer Galle

1979 "Overcrowding in the home: An empirical investigation of its possible pathological consequences." American Sociological Review 44:59-80.

Hassen, Riaz

1977 "Social and psychological implications of high population density." Civilizations 27:228244.

1978 "Singapore children in high-rise flats." Ekistics 45:374-375.

Jain, Uday

1987 The Psychological Consequences of Crowding. Newbury Park, Calif.: Sage.

Joreskog, Karl G., and Dag Sorbom

1989 LISREL 7: A Guide to the Program and Applications. 2nd ed. Chicago: SPSS, Inc. Klausner, William L.

1972 "The cool heart." In Reflections in a Log Pond, ed. William L. Klausner, 45-52. Bangkok, Thailand: Suksit Siam.

1981 "Avoidance of confrontation." In Reflections on Thai Culture, ed. William J. Klausner, 196-198. Bangkok, Thailand: Suksit Siam.

Levi, Lennart, and Lars Andersson

1975 Psycho-social Stress: Population, Environment and Quality of Life. New York: Halsted. Levy, Leo, and Allen Herzog

1974 "Effects of population density and crowding on health and social adaptation in The Netherlands." Journal of Health and Social Behavior 15:288-240.

$\rightarrow$ Loo, Chalsa, and Paul Ong

1984 "Crowding perceptions, attitudes, and consequences among the Chinese." Environment and Behavior 16:55-87.

Marsella, Anthony, Manuel Escudero, and Paul Gordon

1970 "The effects of dwelling density on mental disorders in Filipino men." Journal of Health and Social Behavior 11:288-294.

Milgram, Stanley

1970 "The experience of living in cities." Science 167:1461-1468.

Mirowsky, John, and Catherine Ross

1989 Social Causes of Psychological Distress. New York: Aldine.

Mitchell, Robert

1971 "Some social implications of high density." American Sociological Review 36:18-29. National Statistical Office.

1983 Population and Housing Census: Bangkok Metropolis. Bangkok, Thailand: National Statistical Office. 
$\rightarrow$ Preuss, Gary G.

1981 "The effects of density and urban resistence on voter turnout." Population and Environment 4:246-265.

Rodin, Judith, and Andrew Baum

1978 "Crowding and helplessness: Potential consequences of density and loss of control." In Human Response to Crowding, ed. Andrew Baum and Yokav M. Epstein, 389-401. Hillsdale, N.J.: Lawrence Erlbaum Associates.

Schmitt, Robert

1966 "Density, health and social disorganization." Journal of the American Institute of Planners 32:37-40.

Sherrod, Drury R., and Sheldon Cohen

1979 "Density, personal control, and design." In Residential Crowding and Design, ed. John Aiello and Andrew Baum, 217-227. New York: Plenum.

$\rightarrow$ Sternstein, Larry

1984 "The growth of the population of the world's pre-eminent 'primate city': Bangkok at its bicentenary." Journal of Southeast Asian Studies 15:43-68.

$\rightarrow$ Stokols, Daniel

1972 "A social-psychological model of human crowding phenomena." Journal of the American Institute of Planners 38:72-83.

1978 "A typology of crowding experiences." In Human Response to Crowding, ed. Andrew Baum and Yokav M. Epstein, 219-255. Hillsdale, N.J.: Lawrence Erlbaum Associates. United Nations

1985 Compendium of housing statistics, 1983. 4th ed. New York: United Nations Department of International Economic and Social Affairs, Statistical Office.

Welford, Alan T.

1974 "Stress and performance." In Man Under Stress, ed. Alan T. Welford, 1-14. New York: Halsted.

\section{Appendix Scales and Selected Items}

\section{Independent Variables}

\section{Objective Crowding (3 items)}

(a) Persons per room. Number of persons living in housing unit divided by number of rooms in housing unit.

(b) Persons per 100 square meters. Number of persons living in housing unit times 100 divided by the number of square meters in the dwelling unit.

(c) Others per room. Number of person-hours that other household members are present during the time that the respondent is at home and awake divided by the number of rooms. If one person is present for one hour, this equals one person-hour.

Measurement notes: Logged forms of these variables are used. Errors in log of others per room are correlated with errors in log of persons per 100 square meters.

Alpha for the unweighted scale is .78.

\section{Subjective Crowding (4 items)}

The response categories are strongly agree, agree, disagree, and strongly disagree.

(a) At home, there are too many people around.

(b) In this house, I have almost no time alone.

(c) In my home, people get in each other's way.

(d) At home, I don't have enough room to do things conveniently. 
Measurement notes: Error terms are not correlated.

Alpha for the unweighted scale is $\mathbf{. 8 0}$.

\section{Dependent Variables}

\section{Marital Instability (4 items)}

This introduction was used for the following items:

A lot of people have quarrels with their husband/wife and get so angry that they ask them to leave home or they threaten to leave home themselves.

The response categories are Yes/No for each item.

(a) Has this ever happened in your marriage?

(b) Has the thought of getting a divorce or separation crossed your mind in the past three years?

(c) Have you or your husband/wife ever seriously suggested the idea of divorce within the last three years?

(d) Have you discussed divorce or separation with a close friend?

Measurement notes: Error terms for items $\mathrm{c}$ and $\mathrm{d}$ are correlated.

Alpha for the unweighted scale is .79 .

\section{Marital Arguments (7 items)}

The following introduction was used for items (a) through (f). Now I'm going to read you some things that husbands and wives sometimes agree about and sometimes disagree about. Would you tell me how often each of these caused differences of opinion or were problems in your marriage during the past few weeks?

Same response categories as for marital instability.

(a) Being too tired and not wanting to do anything?

(b) Irritating habits?

(c) Spending money?

(d) Being away from home?

(e) Talking to other men/women too often?

(f) Drinking alcohol or gambling?

(g) How often do you and your husband/wife have serious arguments or fights?

Measurement notes: Error terms are correlated for the following pairs of items: $a$ and b, $c$ and $\mathrm{d}$, and $\mathrm{d}$ and $\mathrm{e}$.

Alpha for the unweighted scale is .70 .

\section{Marital Companionship (4 items)}

The following introduction was used for items (a) through (d). I'm going to read you some things that married couples sometimes do together. Please tell me how often you and your husband/wife have done them in the past month.

Response categories are the same as for marital instability.

(a) Had a good laugh together or shared a joke?

(b) Showing love, affection, and caring toward each other?

(c) Have small talk with each other?

(d) Did something the other particularly appreciated?

Measurement terms: Error terms are correlated for items c and d. Alpha for the unweighted scale is .77 . 


\section{Supportive Behavior (4 items)}

The interviewer selected the respondent's child closest to age 13. If the child was less than 5 years old, items a and b were skipped, and the scale value is undefined. The response categories are never, rarely, sometimes, and often.

(a) How often do you have a long talk with —?

(b) How often do you compliment _—, that is, tell him how good he is, or what a good job he has done?

(c) How often are you able to cheer up when he is unhappy?

(d) How often do you show love toward -?

Measurement notes: Error terms are not correlated.

Alpha for the unweighted scale is .68.

\section{Parent-Child Tension (5 items)}

The response categories are never, rarely, sometimes, and often.

(a) How often is it a relief when your children are out of the house?

(b) How often do your children get in the way (physically)?

(c) How often do you get upset because your children are too noisy?

(d) How often do you wish you could get away from your children?

(e) How often do you feel you can't do what you want to do because you have children? Measurement notes: Error terms for item a are correlated with errors in items b and e. Alpha for the unweighted scale is .69 .

\section{Discipline of Children (4 items)}

If the children were less than 5 years old, items a and b were skipped, and the scale value is undefined.

The response categories are never, rarely, sometimes, and often.

(a) How often do you have to talk to your child(ren) to explain what behavior is appropri-

ate and what behavior is not appropriate?

(b) How often do you have to scold your child(ren)?

(c) How often do you have to punish your child(ren) by pinching or slapping him?

(d) How often do you have to punish your child(ren) by hitting him severely?

Measurement notes: Error terms are correlated for items $a$ and $b$ and for items $c$ and $d$.

Alpha for the unweighted scale is .61 .

\section{Intervening Variables}

\section{Felt Demands (4 items)}

The response categories are no, undecided, and yes.

(a) Does it seem as if others are always making demands on you?

(b) At home, does it seem as if you almost never have any peace and quiet?

(c) At home, does it seem as if you always are having to do something for someone else?

(d) When you try to do something at home, are you almost always interrupted?

Measurement notes: Error terms are correlated for items a and c.

Alpha for the unweighted scale is .68. 


\section{Psychological Distress (10 items)}

The response categories are never, rarely, sometimes, and often for items (a) through (j).

(a) Anxious about something or someone?

(b) That people are trying to pick quarrels or start arguments with you?

(c) So depressed that it interferes with your daily activities?

(d) That personal worries were getting you down physically, that is making you physically ill?

(e) Moody?

(f) Felt you were confused, frustrated, and under a lot of pressure?

(g) Are you ever bothered by nervousness, i.e., by being irritable, fidgety, or tense?

(h) Do you ever feel that nothing ever turns out for you the way you want it to?

(i) Do you have trouble concentrating or keeping your mind on what you are doing?

(j) Are you the worrying type-you know, a worrier?

$$
1 \text { No } 2 \text { Yes }
$$

Measurement notes: Error terms are correlated for the following pairs of items: $d$ and $h, e$ and $f, g$ and $h$, and $i$ and $j$.

Alpha for the unweighted scale is .84 .

\section{Control Variables}

\section{Household Control (3 items)}

The response categories are strongly disagree, disagree, agree, strongly agree.

(a) When I want to move a piece of furniture in the all-purpose room, I can go ahead and move it without asking if others agree.

(b) If I want to invite a friend to visit my house and be entertained (have a good time), I can go ahead and invite him without asking if others agree.

(c) If one of my relatives comes to visit from up-country, I feel free to invite him to stay here for several days. I don't have to ask others if they agree.

Measurement notes: Error terms are not correlated.

Alpha for the unweighted scale is .85 .

\section{Housing Satisfaction (11 items)}

The response categories are strongly dissatisfied, dissatisfied, satisfied, and strongly satisfied. The eleven specific aspects of housing are: drinking water, water for washing, ventilation, bathroom, kitchen, toilet, brightness-sunlight, laundry, noise, smell, and heat. Factor analyses suggest that these 11 items could be divided into three factors. However, for current purposes we form a single scale for these items.

Measurement notes: Error terms are not correlated.

Alpha for the unweighted scale is .85 .

\section{Family Income}

There are ten response categories from below 2,000 baht to more than 20,000 baht per month. At the time of the survey, $\$ 1.00$ (U.S.) $=25$ baht (Thailand). 